\title{
A DISCIPLINA DE POLÍTICA EDUCACIONAL EM CURSOS DE FORMAÇÃO DE PROFESSORES
}

\author{
THE DISCIPLINE OF EDUCATION POLICY IN TEACHER \\ EDUCATION COURSES \\ LA ASIGNATURA DE POLÍTICA EDUCACIONAL EN CURSOS DE FORMACIÓN DE PROFESORES
}

Simone de Fátima Flach

Doutorado em Educação pela Universidade Federal de São Carlos - UFSCar. Docente do Departamento de Educação e do Programa de Pós-graduação em Educação da Universidade Estadual de Ponta Grossa - UEPG | Brasil E-mail: eflach@uol.com.br

Gisele Masson Doutorado em Educação pela Universidade Federal de Santa Catarina - UFSC. Docente do Departamento de Educação e do Programa de Pós-graduação em Educação da Universidade Estadual de Ponta Grossa - UEPG | Brasil

E-mail: gimasson@uol.com.br

\begin{abstract}
REVISTA PEDAGÓGICA
Revista do Programa de Pós-graduação em Educação da Unochapecó | ISSN 1984-1566

Universidade Comunitária da Região de Chapecó | Chapecó-SC, Brasil Como referenciar este artigo: FLACH, S. F. MASSON, G. A disciplina de política educacional em cursos de formação de professores. Revista Pedagógica, Chapecó, v.16, n.33, p. 205-220, Jul./Dez. 2014.
\end{abstract}

RESUMO: O presente artigo destaca a importância da disciplina de Política educacional na formação de professores. Algumas concepções teóricas que sustentam a organização da disciplina e do estudo sobre políticas educacionais são apresentadas, bem como alguns conhecimentos imprescindíveis para a formação de professores. Com base nessas reflexões, discute-se como estão estruturados os conhecimentos relativos à área de Política educacional em diferentes currículos em uma instituição de Ensino Superior do Paraná - Brasil. O estudo foi realizado a partir de análise documental das ementas das disciplinas da área em diferentes cursos de formação de professores. Conclui-se que a disciplina é de suma importância para a formação de professores. No entanto, a área fragiliza-se em razão da descontinuidade do trabalho desenvolvido pelos professores responsáveis pelas disciplinas em razão de contratos de trabalho precários e da não vinculação com a pesquisa do campo da Política educacional.

PALAVRAS-CHAVE: Política Educacional. Ensino de Política Educacional. Formação de Professores.
ABSTRACT: This paper highlights the importance of the discipline of Education policy in teacher education. Some theoretical concepts that support the organization of the discipline and the study on educational policies are presented, as well as some essential knowledge to teacher education. Based on these reflections, we discuss how knowledge of the area of Education policy is structured in different curricula in a higher education institution of Parana - Brazil. The study was conducted from documentary analysis of the discipline syllabuses of the area in different teacher education courses. We concluded that the discipline is of paramount importance to teacher education. However, the area becomes fragile due to the discontinuation of the work developed by the teachers responsible for the disciplines because of insecure employment contracts and no binding with the research field of Education policy.

KEYWORDS: Education Policy. Teaching Education Policy. Teacher education. 


\section{INTRODUÇÃO}

Tratar sobre a disciplina de política educacional na formação de professores, no atual contexto brasileiro, é tarefa complexa. Implica entender o campo específico de estudo e investigação, denominado Política Educacional, suas relações com os encaminhamentos políticos e, ainda, a interpretação de políticas e programas educacionais e sua vinculação com determinadas concepções predominantes num momento histórico específico. A partir dessas questões, é possível inferir sobre o significado da disciplina na formação de professores, sua contribuição para a compreensão de aspectos amplos e específicos da política educacional e, consequentemente, na atuação dos professores na realidade escolar.

Quanto à produção específica sobre o ensino de política educacional na formação de professores, ressaltase ser esta restrita no contexto brasileiro, visto que os estudos a respeito dessa temática centram-se na Política Educacional em geral, programas e projetos educacionais ou políticas educacionais para a formação de professores. O trato sobre o ensino da disciplina de política educacional mostra-se, ainda, um campo aberto para pesquisadores brasileiros.

Nesse sentido, o estudo sobre o ensino de política educacional nos currículos de formação de professores nos parece ainda um campo a ser explorado. Por esse motivo, o trabalho aqui apresentado é uma reflexão inicial, a qual pretende analisar a organização do ensino de política educacional, identificando os aportes teóricos que fundamentam a organização curricular de disciplinas da área de política educacional, nos currículos dos cursos de formação de professores.

Portanto, o objeto deste trabalho é a disciplina de política educacional, de forma a oferecer reflexão sobre os conhecimentos necessários para que os futuros professores atuem criticamente no contexto da prática educativa. Para tanto, procurar-se-á apresentar como está prevista a organização das disciplinas afetas à área Política Educacional, em diferentes cursos de formação de professores, na Universidade Estadual de Ponta Grossa - UEPG - Brasil, evidenciando o enfoque epistemológico identificado nas ementas das disciplinas de 13 cursos de Licenciatura. Ainda, pretende-se apresentar a fragilidade da área em razão da situação laboral, formação e produção acadêmica dos docentes envolvidos nas disciplinas.

Para empreender a análise da Política Educacional, enquanto campo de estudo e pesquisa, é necessário explicitar a base teórica sobre a qual se pretende construir os argumentos necessários para validar o que se pretende discutir. Assim, esclarecemos que a concepção teórica 
que norteia o presente estudo é o materialismo histórico e dialético. Segundo esse referencial teórico-metodológico, a realidade, em um primeiro momento, é 'caótica' sendo possível desvelar essa visão distorcida a partir das contradições que se expressam entre singularidade, particularidade e universalidade. Dessa forma, pretendese, a partir de uma percepção genérica da área de Política Educacional se chegar ao movimento concreto do ensino na disciplina de Política Educacional.

A disciplina Política Educacional envolve conhecimentos de diferentes campos, tais como: conhecimentos sociológicos, políticos, históricos, econômicos, jurídicos, dentre outros. Em que pese a necessidade da interlocução com outras áreas do conhecimento científico, a Política Educacional se constitui em disciplina ímpar, pois oferece a oportunidade de entender as diferentes concepções e matrizes teóricas dessas áreas no contexto da prática política. Nessa perspectiva, o ensino da política educacional é dinâmico, articulando-se com as ações governamentais em dado momento histórico, possibilitando que as contradições sejam visualizadas, não apenas nos textos normativos, mas nas práticas dos gestores públicos. Essa forma de entender o ensino da disciplina supera o caráter do ensino normativo-legal em que a área surgiu, para assumir uma perspectiva dialética materialista de compreensão da realidade educacional.

É preciso destacar que, assim como em outras áreas da educação, o ensino de Política Educacional não é neutro e sempre esteve vinculado a determinados interesses. No Brasil, o ensino de Política Educacional, na formação de professores, foi introduzido no período de influência tecnicista, quando através do Parecer $n^{0}$ 252/69 a disciplina de Estrutura e Funcionamento do Ensino passou a integrar os currículos dos cursos de formação de pedagogos e, posteriormente, também os currículos das Licenciaturas. É importante destacar que, inicialmente, a disciplina foi organizada visando formar os 'técnicos' em educação e, por isso mesmo, as determinações legais se faziam presentes não apenas como necessidade de conhecer o campo educacional, mas como algo que precisava ser cumprido para que a educação pudesse oferecer possibilidades de desenvolvimento para o país. Posteriormente, o ensino de política educacional sofreu inúmeras mudanças, tanto de denominação quanto de organização curricular, sendo que, a partir da reabertura política, em meados dos anos de 1980, a área assumiu um caráter crítico, oferecendo reflexões a respeito da conjuntura social, política e econômica que influenciava os encaminhamentos educacionais inseridos no contexto de redemocratização do país. Nesse período, a preocupação com os encaminhamentos político-educacionais assume a centralidade no debate educacional, principalmente na expectativa de superar problemas históricos da educação 
brasileira, em especial o fracasso escolar e a democratização do acesso. Os estudos de Saviani (1980, 1987), Freitag (1984), Rodrigues (1985), dentre outros, colaboraram para o entendimento da área na formação de professores e a necessidade de superação de um viés tecnicista (e mesmo crítico-reprodutivista) para assumir uma perspectiva que poderíamos denominar de dialética na condução do ensino de Política Educacional. A partir dos anos de 1990, com a expansão do ideário neoliberal no contexto social, econômico e político, a discussão sobre a política educacional abre espaço para diferentes interlocutores com concepções distintas, as quais evidenciam, por um lado, a validação de ações neoliberais que fortalecem a expansão capitalista e, por outro, propostas de transformação social, pautadas na perspectiva democrática em defesa dos interesses e necessidades da classe trabalhadora. A disputa desses projetos se materializou de forma contraditória em diferentes documentos normativos e orientadores das políticas educacionais em curso e, consequentemente, na organização da disciplina e na prática dos professores de Política Educacional.

Na trama em que o ensino de Política Educacional está situado, torna-se necessário explicitar alguns enfoques teóricos que se fazem presentes no ensino da disciplina, como também apontar conhecimentos fundamentais que auxiliam o entendimento da realidade. Essas indicações pretendem colaborar para uma compreensão sobre o ensino de Política Educacional e oferecer suporte teórico para a análise sobre como a disciplina se organiza em diferentes cursos de formação de professores.

\section{ALGUMAS CONCEPÇÕES TEÓRICAS PRESENTES NO ENSINO DE POLÍTICA EDUCACIONAL}

Tanto a análise das políticas quanto o ensino do campo pressupõem a tomada de posição em relação ao referencial teórico a ser utilizado como fundamento para o trabalho a ser desenvolvido, contribuindo para a construção de quadro conceitual consistente que possibilite o entendimento do campo específico da Política Educacional. Visando colaborar para a análise do ensino e organização da disciplina de Política Educacional na formação de professores, apresentamos alguns posicionamentos que auxiliam na investigação do campo e na análise da disciplina. Para tanto, apontamos aqueles que julgamos os mais presentes na organização da disciplina em foco: aqueles que têm como ênfase um posicionamento jurídico-normativo, interpretação do cotidiano educacional e a interpretação marxista.

Para explicar o enfoque jurídico-normativo 
recorremos às reflexões de Ruiz (2013), quando afirma que, na pesquisa da Política Educacional, o investigador considera como unidade principal de análise a norma educativa. Entende que na norma educativa se insere tanto a legislação advinda do poder legislativo quanto as normas advindas do poder executivo, assim como interpretações judiciais (jurisprudência) a respeito da execução de políticas educacionais.

O estudo sobre Política Educacional pressupõe uma análise do Estado e de sua organização política. Na atual sociedade, a organização política do Estado é regulada pelo aparato normativo aceito e positivado em leis, decretos, resoluções, regulamentos e mesmo em jurisprudência sobre fatos afetos à educação. Dessa forma, o ensino de Política Educacional, pautado nesse enfoque, vincula-se ao estudo do aparato legislativo formal e suas interfaces com a execução das políticas educacionais por determinado governo e em determinado momento histórico.

Nesse sentido, são esclarecedoras as reflexões de Ruiz (2013), quando aborda a questão:

Se concentra em el estúdio de las tensiones, negociaciones, acuerdos y conflictos que se dan dentro del Estado em relación com la configuración eimplementación de la práctica institucionalizada de educación dentro de uma formación histórica em partícula. (Ruiz, 2013, p. 122).

Em contrapartida, o ensino de política educacional na perspectiva jurídico-normativa considera não apenas a implementação de normas, mas entende que as políticas educacionais expressam o resultado de uma correlação de forças existente desde a elaboração legislativa até a execução de ações específicas no campo educacional. Nesse sentido, a legislação não é entendida como algo dado e a ser executado, mas como possibilidade de interpretação e implementação, a partir das possibilidades da realidade concreta.

Ainda, Ruiz (2013) alerta que, nessa perspectiva, não pode haver descuido no estudo sobre os princípios culturais e sociais que fundamentam as normas em análise, ocorrendo relevância na explicitação das bases ideológicas que as sustentam.

No entanto, defendemos que a disciplina de Política Educacional, pautada nesse enfoque, precisa considerar que as normas emanadas de diferentes poderes estatais sempre 
estão atravessadas por conflitos e interesses. Explicitar tais conflitos e interesses é tarefa essencial dos professores envolvidos com a disciplina de Política Educacional, sob pena de a área ser minimizada a um posicionamento linear onde a norma dita as regras que deverão ser fielmente cumpridas, sem um movimento dialético entre a esfera da obrigatoriedade e da necessidade de determinadas ações.

Em relação à organização do estudo da Política Educacional a partir da interpretação do cotidiano, considera-se a prática cotidiana, em especial aquela que ocorre na escola, como o eixo central para a análise das políticas educacionais.

Segundo Asprella (2013), busca-se o significado da Política Educacional na vida cotidiana da escola, nas relações entre as políticas e os sujeitos envolvidos na sua execução. Assim, nessa perspectiva, a implementação das políticas educacionais se vincula na cotidianidade de cada escola em particular, sendo as práticas escolares institucionalizadas determinantes nesse processo. Dessa forma, considera-se que, pelo fato de as escolas serem diferentes, a implementação de políticas é variável de uma escola para outra.

Ao discutir o cotidiano como pressuposto da pesquisa, Garcia (2003) considera este como eixo central, tendo a ação cotidiana como critério de verdade, sendo ela que convalida a teoria. Nessa perspectiva,

Partimos da prática, vamos à teoria a fim de a compreendermos e à prática retornamos com a teoria ressignificada, atualizada, recriada, dela nos valendo para melhor interferirmos na prática. (Garcia, 2003, p. 12)

Entendemos que o ensino de política educacional sob esse enfoque procura revelar as ações políticas nas práticas educativas, tendo o cotidiano como referência primeira e enfatizando questões como: cultura institucional, prática escolar, construção da subjetividade, diversidade e diferença. A partir dessas questões, é possível vislumbrar que o ensino de política pode enfatizar o protagonismo dos sujeitos, valorizando a comunidade educativa como responsável pelo processo de democratização, fiscalizadora da educação como direito de todos; a autonomia escolar sendo entendida como uma nova forma de controle interno e enfatizando a responsabilidade docente pelos resultados educacionais. Todavia, a concepção de prática é restrita a ação pragmática e não como uma prática social mais ampla.

Outro enforque presente no ensino de Política Educacional é aquele que assume a perspectiva marxista, de forma a explicitar o real a partir de suas contradições e relações entre o singular, o particular e o universal. 
O real é analisado a partir de seu desenvolvimento histórico, de sua gênese e desenvolvimento, captando as categorias mediadoras que possibilitam a apreensão na totalidade. (Masson; Mainardes, 2013). Dessa forma, o enfoque marxista pressupõe que o significado de uma política educacional precisa de uma compreensão sobre a lógica global do sistema de produção. Os determinantes econômicos, históricos, políticos e culturais ajudam a explicar os encaminhamentos político-educacionais em determinado contexto. Nesse sentido, o ensino da Política Educacional não pode ocorrer desvinculado das manifestações sociais, das múltiplas relações, particularidades e detalhes que possibilitam captar o movimento em sua totalidade, revelando sua essência. Isso quer dizer que a correlação de forças existentes no processo de elaboração e implementação de determinada política precisa ser considerado para que o seu significado seja apreendido.

Para além dessas questões, a disciplina de Política Educacional, pautada nesse enfoque, tem o compromisso de não desvincular o método do conteúdo da obra marxiana. Isso quer dizer que as categorias do método (contradição, práxis, mediação, totalidade, historicidade) orientam e se complementam numa relação dialética com as categorias de conteúdo (antagonismo de classe, relação capital-trabalho, mais valia, ideologia e Estado). As categorias de método e conteúdo possibilitam desvendar determinada política educacional por inteiro, evidenciando a correlação de forças presentes no processo de elaboração e implementação das políticas educacionais.

Consideramos que o enfoque marxista na disciplina de política educacional contribui para uma compreensão crítica da realidade educacional, oferecendo aos futuros professores os instrumentos possíveis para uma intervenção na realidade, com vistas à superação da sociedade regida pela lógica do capital. Esse compromisso social e político é eixo fundamental na organização da disciplina.

Sem dúvida outros enfoques estão presentes não apenas nas investigações sobre as políticas educacionais, como na organização das disciplinas que têm por objetivo discutir a organização político-educacional em cursos de formação de professores. No entanto, por se caracterizar em estudo inicial sobre a temática, elegemos aquelas que julgamos mais presentes no encaminhamento pedagógico das disciplinas da área da política educacional e que poderão oferecer um primeiro embasamento para as análises propostas.

A seguir, apresentamos os conhecimentos que consideramos fundamentais para o ensino de Política Educacional em cursos de formação de professores 


\section{CONHECIMENTOS ESSENCIAIS PARA O ENSINO DA DISCIPLINA DE POLÍTICA EDUCACIONAL}

Considerando o referencial teórico adotado, destacamos que há conteúdos que são fundamentais, por serem universais, e outros que são acessórios para a compreensão da política educacional, para futuros profissionais da educação. Neste texto, apresentaremos os conhecimentos que julgamos universais, ou seja, conteúdos são imprescindíveis para o estudo da disciplina. Assim, elencamos tais conteúdos a seguir:

1- Estudo das características fundamentais da sociedade capitalista: luta de classes, relações sociais de produção, antagonismo entre capital e trabalho.

A educação é um complexo parcial no conjunto da totalidade social, por isso, é importante o estudo do movimento e das contradições que caracterizam a sociedade capitalista. Isso significa que não é possível tratar da política educacional separadamente da organização da sociedade na qual ela está inserida. A compreensão de um determinado período histórico pressupõe, portanto, a apreensão elementar do conjunto da sociedade. Sendo assim, a política educacional deve ser estudada a partir de um conjunto amplo de relações, particularidades e detalhes, a fim de captá-la em seu movimento no conjunto da totalidade social.

2- Estudo do papel do Estado na definição das políticas educacionais

As políticas educacionais, como políticas públicas, representam o Estado em ação, ou seja, aquilo que o governo decide ou não fazer. Por isso, as políticas educacionais só poderão ser adequadamente analisadas se houver um estudo do Estado moderno e suas transformações históricas na sociedade capitalista. Além disso, é fundamental a análise da diferença entre Estado e governo, a fim de que as políticas educacionais, ao serem analisadas, não percam de vista como o Estado se organiza e as influências dos diferentes governos, com seus diferentes partidos políticos, na construção de um determinado projeto de sociedade e de educação.

\section{3- O campo da política educacional}

A política educacional ainda é considerada, na América Latina, como um campo em construção, pois se considera que as investigações ainda carecem de referenciais analíticos consistentes e uma definição mais clara do objeto de investigação. De acordo com Azevedo (2004), no Brasil, os estudos sobre políticas públicas, de um modo geral, ganharam centralidade somente a partir da 
década de 1980, vinculados à Ciência Política e à Sociologia. Ao mesmo tempo, destacamos, a partir de estudos de Stremel (2012, p.11), que "nos últimos anos, a pesquisa sobre políticas educacionais vem se expandindo de forma significativa, assim como as publicações e o interesse dos pesquisadores pelas políticas educacionais está se ampliando.” Esse debate específico do campo é importante que seja abordado na disciplina de Política Educacional para que o aluno compreenda que está estudando uma área do conhecimento que precisa ser consolidada no conjunto das pesquisas em educação, no Brasil.

\section{4- A organização da educação escolar}

É importante que o futuro professor tenha clareza sobre como a educação escolar brasileira se organiza, entendendo que há variações entre diferentes países e mesmo em momentos históricos distintos da realidade brasileira. Nesse sentido, a organização da educação deve ser estudada a partir da sua historicidade, pois isso contribuirá para a compreensão das prioridades das políticas educacionais nos diferentes períodos da história da educação brasileira.

\section{5- Aspectos legais da educação brasileira}

Toda política educacional é implementada a partir de Planos Nacionais, Estaduais e Municipais, de programas de governo, de Leis, de Resoluções etc. Desse modo, somente é possível compreender a organização da educação escolar brasileira se considerarmos as normatizações legais que a regulam. Todavia, é imprescindível que o conjunto de dispositivos legais seja trabalhado de modo articulado com o contexto em que foi concebido. Isso quer dizer que é fundamental fazer relações com o momento histórico em que foram concebidos, o governo que estava no poder, os sujeitos que trabalharam diretamente na elaboração do documento legal, as disputas no processo de definição, bem como os avanços e recuos no conjunto da correlação de forças que compõe o Estado (empresários, trabalhadores, profissionais da educação, grupos religiosos, movimentos sociais etc.).

Nosso objetivo, ao destacar tais conhecimentos, não é engessar o ensino de Política Educacional, a partir de uma lista de conteúdos, mas enfatizar a importância de tais conhecimentos para uma formação que não recaia numa abordagem meramente jurídico-normativa e muito menos numa abordagem singularizada do cotidiano escolar.

Na sequência do texto, abordaremos especificamente a disciplina de Política Educacional, nos cursos de formação de professores, da Universidade Estadual de Ponta Grossa. 


\section{A DISCIPLINA DE POLÍTICA EDUCACIONAL NOS CURSOS DE FORMAÇÃO DE PROFESSORES DA UEPG}

A contribuição de disciplinas que tenham a política educacional como eixo é inquestionável para a formação de professores, visto que oferece, ao futuro profissional, estudos, discussões e reflexões a respeito das interfaces das políticas educacionais com a realidade onde estarão atuando.

Com o objetivo de refletir sobre a importância da disciplina no contexto da universidade e da formação dos estudantes, buscou-se apresentar como estão estruturados os conhecimentos das disciplinas da área da Política Educacional em diferentes cursos de formação de professores da Universidade Estadual de Ponta Grossa Paraná - Brasil.

Assim, a coleta de dados centrou-se, num primeiro momento, na busca das ementas das disciplinas da área de política educacional em diferentes cursos de formação de professores, localizando em quais disciplinas estão presentes os conhecimentos relativos à área e a carga horária prevista para o cumprimento das ementas. Esses dados são relevantes porque tanto sinalizam para o enfoque presente na disciplina, quanto para a importância da área no contexto do curso.

Esses dados podem ser visualizados no quadro a seguir:

QUADRO 1 - Disciplinas que contemplam conhecimentos específicos sobre política educacional em diferentes cursos de licenciaturas na UEPG - 2014.

\begin{tabular}{|c|c|c|c|}
\hline Cursos & Disciplina & $\begin{array}{l}\text { Carga } \\
\text { Horária }\end{array}$ & Ementa da disciplina \\
\hline $\begin{array}{l}\text { Licen- } \\
\text { ciatura } \\
\text { em Artes } \\
\text { Visuais }\end{array}$ & $\begin{array}{l}\text { Políticas } \\
\text { Públicas e } \\
\text { Educacionais } \\
\text { no Brasil }\end{array}$ & $68 \mathrm{~h}$ & $\begin{array}{l}\text { Políticas Públicas e Educacio- } \\
\text { nais no Brasil: Análise das re- } \\
\text { lações entre educação, estado } \\
\text { e sociedade. As relações entre } \\
\text { educação, trabalho e cidada- } \\
\text { nia. Estudo da organização da } \\
\text { Educação Brasileira: dimen- }\end{array}$ \\
\hline $\begin{array}{l}\text { Licencia- } \\
\text { tura em } \\
\text { Música }\end{array}$ & $\begin{array}{l}\text { Políticas } \\
\text { Públicas e } \\
\text { Educacionais } \\
\text { no Brasil }\end{array}$ & $68 \mathrm{~h}$ & $\begin{array}{l}\text { sões históricas, políticas, } \\
\text { sociais, econômicas e educa- } \\
\text { cionais. Políticas públicas e } \\
\text { educacionais no Brasil desde } \\
\text { os jesuítas. Análise da educa- } \\
\text { ção na Constituição Federal } \\
\text { de } 1988 \text { e a Lei de Diretrizes e } \\
\text { Bases da Educação Nacional } \\
\text { (Lei no 9394/96). Sistema } \\
\text { educacional brasileiro. Análise } \\
\text { dos níveis e modalidades de } \\
\text { ensino: DCN. Lei n }{ }^{\circ} 8.069 / 90 \\
\text { (ECA). Lei nº 10.639/o3 } \\
\text { (Afrodescendentes). }\end{array}$ \\
\hline
\end{tabular}




\begin{tabular}{|c|c|c|c|}
\hline Cursos & Disciplina & $\begin{array}{l}\text { Carga } \\
\text { Horária }\end{array}$ & Ementa da disciplina \\
\hline $\begin{array}{l}\text { Licencia- } \\
\text { tura em } \\
\text { Educação } \\
\text { Física }\end{array}$ & $\begin{array}{l}\text { Estrutura e } \\
\text { Funciona- } \\
\text { mento da } \\
\text { Educação } \\
\text { Básica }\end{array}$ & $68 \mathrm{~h}$ & $\begin{array}{l}\text { Estado, sociedade e educação: } \\
\text { interdependência. Estudo da } \\
\text { organização da educação bra- } \\
\text { sileira: dimensões, históricas, } \\
\text { políticas, sociais e econômicas. } \\
\text { A educação nas Constituições } \\
\text { Federais Brasileiras. Pers- } \\
\text { pectivas atuais da Educação } \\
\text { básica na LDB 9394/96. } \\
\text { Modalidades da Educação. } \\
\text { Financiamento da Educação. }\end{array}$ \\
\hline $\begin{array}{l}\text { Licencia- } \\
\text { tura em } \\
\text { Ciências } \\
\text { Biológicas }\end{array}$ & $\begin{array}{l}\text { Estrutura e } \\
\text { Funciona- } \\
\text { mento da } \\
\text { Educação } \\
\text { Básica }\end{array}$ & $51 \mathrm{~h}$ & \multirow{4}{*}{$\begin{array}{l}\text { Análise das relaç̃̃es entre } \\
\text { educação, estado e sociedade. } \\
\text { Estudo da organização da edu- } \\
\text { cação brasileira: dimensões } \\
\text { históricas, políticas, sociais, } \\
\text { econômicas e educacionais. } \\
\text { Análise da educação na Cons- } \\
\text { tituição Federal de } 1988 \text { e a } \\
\text { nova Lei de Diretrizes e Bases } \\
\text { da Educação Nacional (Lei } \\
\text { 9394/96). }\end{array}$} \\
\hline $\begin{array}{l}\text { Licencia- } \\
\text { tura em } \\
\text { Matemá- } \\
\text { tica }\end{array}$ & $\begin{array}{l}\text { Estrutura e } \\
\text { Funciona- } \\
\text { mento da } \\
\text { Educação } \\
\text { Básica }\end{array}$ & $68 \mathrm{~h}$ & \\
\hline $\begin{array}{l}\text { Licencia- } \\
\text { tura em } \\
\text { Física }\end{array}$ & \begin{tabular}{|l} 
Estrutura e \\
Funciona- \\
mento da \\
Educação \\
Básica \\
\end{tabular} & $68 \mathrm{~h}$ & \\
\hline $\begin{array}{l}\text { Licencia- } \\
\text { tura em } \\
\text { Química }\end{array}$ & $\begin{array}{l}\text { Estrutura e } \\
\text { Funciona- } \\
\text { mento da } \\
\text { Educação } \\
\text { Básica }\end{array}$ & $68 \mathrm{~h}$ & \\
\hline $\begin{array}{l}\text { Licencia- } \\
\text { tura em } \\
\text { Geografia }\end{array}$ & $\begin{array}{l}\text { Estrutura e } \\
\text { Funciona- } \\
\text { mento da } \\
\text { Educação } \\
\text { Básica }\end{array}$ & $68 \mathrm{~h}$ & $\begin{array}{l}\text { Análise das relações entre } \\
\text { Educação, Estado e Sociedade. } \\
\text { Estudo da organização da edu- } \\
\text { cação brasileira: dimensões } \\
\text { históricas, políticas, sociais, } \\
\text { econômicas e educacionais. } \\
\text { Trajetória da Educação nas } \\
\text { Constituições. O avanço da } \\
\text { Sociedade Democrática e a } \\
\text { relação com a Educação na } \\
\text { Constituição Federal de 1988. } \\
\text { A Lei de diretrizes e Bases } \\
\text { da Educação Nacional (Lei } \\
\text { 9.394/96), suas regulamen- } \\
\text { tações posteriores e a relação } \\
\text { com os níveis e modalidades } \\
\text { da Educação. }\end{array}$ \\
\hline
\end{tabular}




\begin{tabular}{|c|c|c|c|}
\hline Cursos & Disciplina & $\begin{array}{l}\text { Carga } \\
\text { Horária }\end{array}$ & Ementa da disciplina \\
\hline $\begin{array}{l}\text { Licencia- } \\
\text { tura em } \\
\text { História }\end{array}$ & $\begin{array}{l}\text { Estrutura e } \\
\text { Funciona- } \\
\text { mento da } \\
\text { Educação } \\
\text { Básica }\end{array}$ & $68 \mathrm{~h}$ & $\begin{array}{l}\text { Análise das relações entre } \\
\text { educação, Estado e sociedade. } \\
\text { Políticas educacionais e finan- } \\
\text { ciamento da educação. Estudo } \\
\text { da organização da educação } \\
\text { brasileira: dimensões históri- } \\
\text { cas, políticas, sociais, econô- } \\
\text { micas e educacionais. Análise } \\
\text { da educação na Constituição } \\
\text { Federal de 1988 e a Lei de } \\
\text { Diretrizes e Bases da Educação } \\
\text { Nacional (Lei 9394/96): níveis } \\
\text { e modalidades de educação e } \\
\text { ensino. Regulamentações pós- } \\
\text {-LDBEN. Parâmetros Curri- } \\
\text { culares Nacionais e Diretrizes } \\
\text { Curriculares Estaduais para a } \\
\text { Educação Básica: visão geral e } \\
\text { contextualizada. }\end{array}$ \\
\hline $\begin{array}{l}\text { Licencia- } \\
\text { tura em } \\
\text { Letras } \\
\text { (Portu- } \\
\text { guês/ } \\
\text { Francês; } \\
\text { Português/ } \\
\text { Inglês e } \\
\text { Português/ } \\
\text { Espanhol) } \\
\end{array}$ & $\begin{array}{l}\text { Estrutura e } \\
\text { Funciona- } \\
\text { mento da } \\
\text { Educação } \\
\text { Básica }\end{array}$ & $68 \mathrm{~h}$ & $\begin{array}{l}\text { A Educação Brasileira a partir } \\
\text { LDBEN 4024/61. Lei de Dire- } \\
\text { trizes e Bases da Educação Na- } \\
\text { cional: Lei 9394/96. Educação } \\
\text { Básica: as propostas do MEC } \\
\text { para a educação brasileira em } \\
\text { seus diversos níveis e mo- } \\
\text { dalidades. Educação Básica: } \\
\text { organização escolar, estrutura } \\
\text { curricular, }\end{array}$ \\
\hline $\begin{array}{l}\text { Licencia- } \\
\text { tura em } \\
\text { Pedagogia }\end{array}$ & $\begin{array}{l}\text { Política e } \\
\text { organização } \\
\text { da Educação } \\
\text { Brasileira }\end{array}$ & $102 \mathrm{~h}$ & $\begin{array}{l}\text { Estudo do sistema educacio- } \\
\text { nal brasileiro, de seus aspectos } \\
\text { organizacionais, de suas po- } \\
\text { líticas e das variáveis interve- } \\
\text { nientes na gestão da Educação } \\
\text { Básica. Análise teórico-prática } \\
\text { da legislação vigente, aplicada } \\
\text { à organização dos Sistemas } \\
\text { e das Instituições Escolares } \\
\text { em seus aspectos políticos, } \\
\text { administrativos, pedagógicos } \\
\text { e financeiros. }\end{array}$ \\
\hline
\end{tabular}

Fonte: As autoras, com base nas informaçoes do Catálogo de Cursos 2014 - UEPG.

Os conteúdos contemplados nas disciplinas indicam aproximação do enfoque jurídico-normativo na maioria dos cursos analisados, pois a legislação vigente (em especial a Constituição Federal e Lei de Diretrizes e Bases da Educação Nacional) é indicada em todas as ementas. No curso de Licenciatura em Pedagogia, a indicação de documentos normativos específicos não é explícita, ocorrendo uma aproximação com a interpretação do cotidiano ao indicar que a análise teórico-prática da legislação se vincula à "organização dos sistemas e das instituições escolares". Todavia, a "análise das relações entre educação, estado e sociedade”, prevista em nove 
cursos, pode aproximar a disciplina de um enfoque marxista, mas essa aproximação está vinculada ao encaminhamento pedagógico e à postura assumida pelos professores responsáveis pelas disciplinas.

Por se caracterizar em estudo inicial, o presente texto não tem a pretensão de classificar as disciplinas analisadas em um ou outro enfoque específico, mas oferecer subsídios que possibilitem uma análise sobre a organização do campo da política educacional. Dessa forma, preliminarmente, entendemos que as ementas das disciplinas analisadas oferecem uma indicação dos conhecimentos básicos contemplados nos Projetos Pedagógicos dos Cursos, representando o resultado da correlação de forças existente no processo de elaboração das ementas.

Ainda, é preciso ressaltar, a partir do referencial adotado pelas autoras, que as ementas das disciplinas não indicam debate específico sobre o campo da política educacional, centrando-se muito mais nos conteúdos de caráter normativo e destes em relação à sociedade e à organização escolar.

No entanto, não sendo explícita a ênfase existente em cada disciplina do campo da política educacional, entendemos que essa tarefa fica sob a responsabilidade de cada professor. A esse respeito, consideramos importante analisar a vinculação dos professores das disciplinas com a universidade e com o campo da política educacional. Para tanto, levantamos a forma de vínculo empregatício existente entre professor e universidade e sua relação com o campo da política educacional, através de sua formação específica e produção científica na área.

A análise sobre o vínculo empregatício é importante em razão da existência de dois tipos de contratos de trabalho no contexto analisado. O vínculo de professor efetivo é aquele em que o profissional é aprovado em concurso público de provas e títulos, tendo estabilidade e progressão funcional na carreira, conforme previsão na Política Docente da instituição. O vínculo de professor temporário é aquele em que o profissional é contratado por tempo determinado (podendo permanecer até dois anos consecutivos) para suprir necessidade temporária em razão do afastamento de professor efetivo ou vacância no cargo, no caso de aposentadorias ou exonerações. Entendemos o vínculo temporário como precário, visto que o profissional não estabelece relação de permanência na instituição e na área específica de atuação, podendo ser remanejado para outra área, conforme necessidade da instituição e do departamento onde estiver lotado.

A análise da produção do professor na área da política educacional é necessária em razão de entendermos que esta pode indicar maior envolvimento com o campo e, consequentemente, uma atuação crítica em relação aos conhecimentos específicos, possibilitando, aos futuros 
professores, aprofundamento científico e maiores condições de intervenção no campo da política educacional.

A respeito dessas questões, o quadro a seguir demonstra a relação entre os professores que ministram disciplinas afetas à área de Política Educacional e a produção acadêmica no campo.

QUADRO 2 - Relação entre ${ }^{0}$ de turmas, vínculo empregatício e produção dos professores responsáveis pelas disciplinas que contemplam conhecimentos específicos sobre política educacional em diferentes cursos de licenciaturas na UEPG - 2014.

\begin{tabular}{|c|c|c|c|c|c|}
\hline \multirow[t]{2}{*}{ CURSOS } & \multirow[t]{2}{*}{$\begin{array}{l}\mathrm{N}^{\circ} \text { de } \\
\text { turmas } \\
\text { por curso }\end{array}$} & \multicolumn{2}{|c|}{$\begin{array}{l}\text { Vínculo Empregatício } \\
\text { dos professores - por } \\
\text { turma }\end{array}$} & \multicolumn{2}{|c|}{$\begin{array}{l}\text { Produção } \\
\text { na área - } \\
\text { professor } \\
\text { por turma }\end{array}$} \\
\hline & & Efetivo & Temporário & Sim & Não \\
\hline $\begin{array}{l}\text { Licenciatu- } \\
\text { ra em Artes } \\
\text { Visuais }\end{array}$ & 01 & . & 01 & & 01 \\
\hline $\begin{array}{l}\text { Licenciatura } \\
\text { em Música }\end{array}$ & 01 & . & 01 & & 01 \\
\hline $\begin{array}{l}\text { Licenciatura } \\
\text { em Educação } \\
\text { Física }\end{array}$ & 01 & . & 01 & & 01 \\
\hline $\begin{array}{l}\text { Licenciatura } \\
\text { em Ciências } \\
\text { Biológicas } \\
\end{array}$ & 02 & 02 &.- & 02 & \\
\hline $\begin{array}{l}\text { Licenciatura } \\
\text { em Matemá- } \\
\text { tica }\end{array}$ & 03 & 03 & - & 01 & 02 \\
\hline $\begin{array}{l}\text { Licenciatura } \\
\text { em Física }\end{array}$ & 01 & . & 01 & & 01 \\
\hline $\begin{array}{l}\text { Licenciatura } \\
\text { em Química }\end{array}$ & 01 & . & 01 & & 01 \\
\hline $\begin{array}{l}\text { Licenciatura } \\
\text { em Geografia }\end{array}$ & 01 & . & 01 & & 01 \\
\hline $\begin{array}{l}\text { Licenciatura } \\
\text { em História }\end{array}$ & 01 & . & 01 & & 01 \\
\hline $\begin{array}{l}\text { Licenciatura } \\
\text { em Letras } \\
\text { (Português/ } \\
\text { Francês; Por- } \\
\text { tuguês/Inglês } \\
\text { e Português/ } \\
\text { Espanhol) }\end{array}$ & $\mathrm{O} 5$ & O5 & - & 01 & 04 \\
\hline $\begin{array}{c}\text { Licenciatura } \\
\text { em Pedagogia }\end{array}$ & 03 & 03 & - & $\mathrm{O} 3$ & \\
\hline Total & 20 & 13 & 07 & 07 & 13 \\
\hline
\end{tabular}

Fonte: As autoras, com base nas informações obtidas no Departamento de Educação/UEPG e CNPQ.

Os dados indicam que, na maioria das turmas, o ensino de política educacional no ano de 2014 esteve sob a responsabilidade de professor efetivo, o que poderia indicar maior envolvimento com o campo. No entanto, ao analisar a produção docente, os dados indicam que o 
vínculo efetivo não garante envolvimento com a produção científica e que os professores com vínculo temporário não estão formalmente ligados à produção científica sobre política educacional.

Entendemos que a área da política educacional, da qual fazem parte disciplinas de diferentes denominações, encontra-se fragilizada devido as seguintes constatações: descontinuidade do trabalho desenvolvido em razão de contratos de trabalho precário e da não vinculação com a pesquisa do campo da política educacional (mesmo quando as disciplinas são ministradas por professores efetivos). Considerando que os conhecimentos sobre política educacional são imprescindíveis para a formação de professores, os dados analisados indicam que essa formação se fragiliza em razão da organização curricular dos cursos e da política laboral, tanto da Universidade quanto do departamento responsável, pela designação de profissionais para a atuação nos cursos de formação de professores.

Essas constatações sinalizam para a necessidade de fortalecimento da área específica, através da ampliação do debate a respeito da contribuição do campo da política educacional para a formação de professores.

\section{CONCLUSÃO}

Ao abordarmos a organização das disciplinas relativas ao campo da política educacional, buscamos destacar sua importância na formação de professores e no contexto da universidade. As diferentes perspectivas teóricas contribuem para o debate do campo da política educacional, tanto no ensino e quanto na pesquisa, contribuindo para fazer avançar essa área de conhecimento. No entanto, a forma como as disciplinas se organizam demonstra que existem contradições para o processo formativo de professores, pois os conteúdos contemplados nas ementas vinculam-se a diferentes perspectivas de análise das políticas educacionais, fragilizando tanto a formação quanto o campo específico.

A partir das questões apontadas, evidencia-se que as disciplinas que contemplam os conhecimentos sobre Política Educacional são de suma importância para a formação de professores. Em contrapartida, ocorre a fragilização da área em razão da descontinuidade do trabalho docente, motivada por contratos de trabalho precário e da não vinculação de muitos professores com a pesquisa do campo da política educacional.

Para concluir, indicamos que as diferentes perspectivas para a análise e o ensino da política educacional ainda precisam ser exploradas no contexto do ensino superior no Brasil, a fim de se desvendar como o 
campo vem se desenvolvendo e contribuindo no processo formativo dos professores.

\section{REFERÊNCIAS}

AZEVEDO, Janete M. Lins de. A educação como política pública. Campinas/SP: Autores Associados, 2004.

ASPRELLA, Gabriel. La interpelación de lo cotidiano a las políticas educativas (políticas educativas, reformas y vida escolar cotidiana). In. TELLO, César. Espistemologías de la política educativa: posicionamientos, perspectivas y enfoques. Campinas, SP: Mercado e Letras, 2013. p. 91 108.

FREITAG, Bárbara. Escola, Estado e sociedade. São Paulo: Moraes, 1984.

GARCIA, Regina Leite (org). Método: pesquisa com o cotidiano. Rio de Janeiro: DP\&A, 2003

GATTI, Bernadete. Democratização do Ensino: uma reflexão sobre a realidade atual. Revista Em Aberto. Brasília: INEP, out./dez. 1989.

MASSON, Gisele; MAINARDES, Jefferson. Las contribuciones de la perspectiva marxista para la investigación sobre políticas educativas. In. TELLO, César. Espistemologías de la política educativa: posicionamientos, perspectivas y enfoques. Campinas, SP: Mercado e Letras, 2013. p. 319 - 343.

SAVIANI, Dermeval. Educação: do senso comum à consciência filosófica. São Paulo: Cortêz/Autores Associados, 1980.

SAVIANI, Dermeval. Escola e Democracia. São Paulo: Cortêz/Autores Associados, 1987.

STREMEL, Silvana. (2012). Fontes para o estudo da constituição do campo da política educacional no Brasil. In: I Jornadas Latinoamericanas de estudios epistemológicos en Política Educativa, Buenos Aires. Anais .2012. p.1-19.

RODRIGUES. Neidson. Por uma nova escola. São Paulo: Cortez, 1985.

RUIZ, Guillermo. El enfoque jurídico normativo de la política educacional. In. TELLO, César. Espistemologías de la política educativa: posicionamientos, perspectivas y enfoques. Campinas, SP: Mercado e Letras, 2013. p. $109-162$. 